\title{
Intestinal Malrotation, Mesocolic Hernia, and Meckel Diverticulum - Differential Diagnosis of Abdominal Pain in Adults: Case Report and Literature Review
}

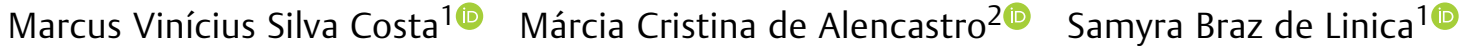 \\ Tiago dos Santos Ferreira ${ }^{30}$ Edson Soares Bezerra ${ }^{40}$ Sérgio Bisogni ${ }^{4}$
}

1 Programa de Residência Médica em Cirurgia Geral, Hospital Santa

Address for correspondence Marcus Vinicius Silva Costa, Avenida Bárbara, Faculdade de Medicina São Leopoldo Mandic, Campinas, São Paulo - SP, Brazil Almeida Garret 1,282, Campinas, 13087291, São Paulo, SP, Brasil

2 Hospital Santa Bárbara, Faculdade de Medicina São Leopoldo (e-mail: mvscosta1@gmail.com).

Mandic, Campinas, São Paulo - SP, Brazil

${ }^{3}$ Department of Radiology, Hospital Estadual Sumaré, Universidade

Estadual de Campinas, São Paulo - SP, Brazil

${ }^{4}$ Urology Department, Hospital Santa Bárbara, Faculdade de

Medicina São Leopoldo Mandic, Campinas, São Paulo - SP, Brazil

J Coloproctol 2021;41(3):325-328.

\begin{abstract}
Intestinal malrotation is a congenital anomaly caused by incomplete rotation or absence of rotation of the primitive intestine along the axis of the upper mesenteric artery during embryonic development. Embryonic development and its anatomical variations were described by Dott in 1923 .

Keywords

- intestinal malrotation

- Meckel diverticulum

- intestinal angina

- Ladd procedure

- chronic abdominal pain

Intestinal malrotation is a rare condition among adults - prevalent in a mere $0.0001 \%$ to $0.19 \%$ of the population -, and it may be associated with other anatomical deformities. It can be asymptomatic or manifest with varying intensity, from obstruction to necrosis of intestinal segments. In general, this abnormality is diagnosed in the first year of life; however, symptoms may appear later in life, making diagnosis in adults difficult on account of non-specific symptoms.

In the present study, we report a case of intestinal malrotation associated with chronic non-specific symptoms progressing to mesenteric angina.
\end{abstract}

\section{Introduction}

Intestinal malrotation is a congenital abnormality caused by incomplete rotation or absence of rotation of the primitive intestine along the axis of the upper mesenteric artery during embryonic development. ${ }^{1-3}$ Embryonic development and its anatomical variations were described by Dott in $1923 .{ }^{4}$

received

July 8,2020

accepted after revision

January 15, 2021
DOI https://doi.org/

$10.1055 / \mathrm{s}-0041-1732327$.

ISSN 2237-9363.
Intestinal malrotation is a rare condition among adults prevalent in a mere $0.0001 \%$ to $0.19 \%$ of the population -, and it may be associated with other anatomical deformities. ${ }^{5}$ It can be asymptomatic or manifest with varying intensity, from obstruction to necrosis of intestinal segments. In general, this abnormality is diagnosed in the first year of life; however, (c) 2021. Sociedade Brasileira de Coloproctologia. All rights reserved.

This is an open access article published by Thieme under the terms of the Creative Commons Attribution-NonDerivative-NonCommercial-License, permitting copying and reproduction so long as the original work is given appropriate credit. Contents may not be used for commercial purposes, or adapted, remixed, transformed or built upon. (https://creativecommons.org/ licenses/by-nc-nd/4.0/)

Thieme Revinter Publicações Ltda., Rua do Matoso 170, Rio de Janeiro, RJ, CEP 20270-135, Brazil 
symptoms may appear later in life, making diagnosis in adults difficult on account of non-specific symptoms. ${ }^{3,6}$

In the present study, we report a case of intestinal malrotation associated with chronic non-specific symptoms progressing to mesenteric angina.

\section{Case Report}

A 65-year-old woman complaining of chronic, intermittent abdominal pain for 5 years, with greater intensity in the umbilical region; the pain worsened after eating. The symptoms intensified, and the patient checked into the emergency room. The cramp-like pain only relieved with the administration prescription opioids. The patient had been submitted to a previous hysterectomy due to myomatosis, and she reported bowel obstruction for the previous five years, which was treated conservatively by her attending physician. The patient avoided large meals because they caused pain, and had lost weight due to intermittent fasting.

The patient was in good physical condition, with a globose abdomen, the presence of borborygmus, tympanitic to percussion, and pain reported upon deep palpation in the umbilical and hypogastric regions. There were no signs of peritonitis.

A computed tomography (CT) scan revealed diverticulosis, twisting of the mesenteric vessels in the umbilical and hypogastric regions with surrounding fat planes blurred and small satellite lymph nodes, and discrete distension of bowel loops in the right iliac fossa.

A magnetic resonance imaging (MRI) angiogram ( - Figures 1 and 2) showed twisting of the mesenteric vessels in the umbilical and hypogastric regions at the midline, suggesting an internal hernia, without signs of bowel obstruction.

An exploratory laparotomy revealed mesenteric torsion of $720^{\circ}$ around the superior mesenteric artery (- Figure $\mathbf{3}$ ), $260 \mathrm{~cm}$ from the ileocecal valve (ICV), presence of Meckel

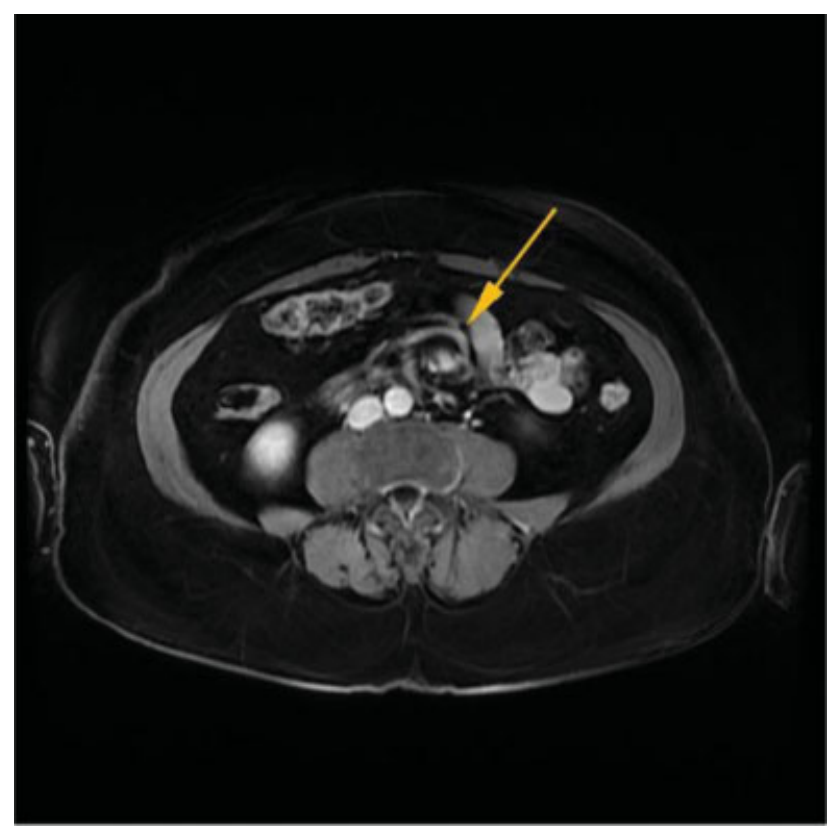

Fig. 1 Twisting of the mesenteric vessels on magnetic resonance imaging (MRI) suggesting intestinal malrotation.

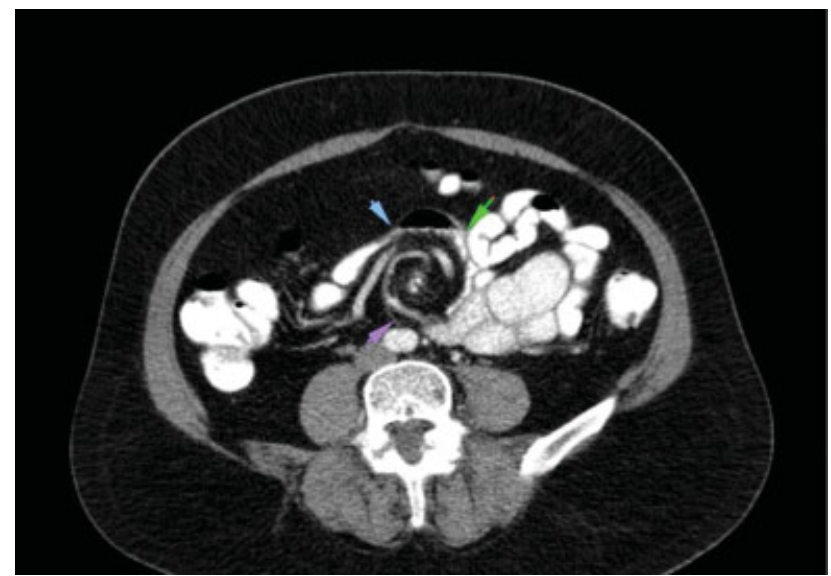

Fig. 2 Twisting of the mesenteric vessels on MRI suggesting intestinal malrotation.

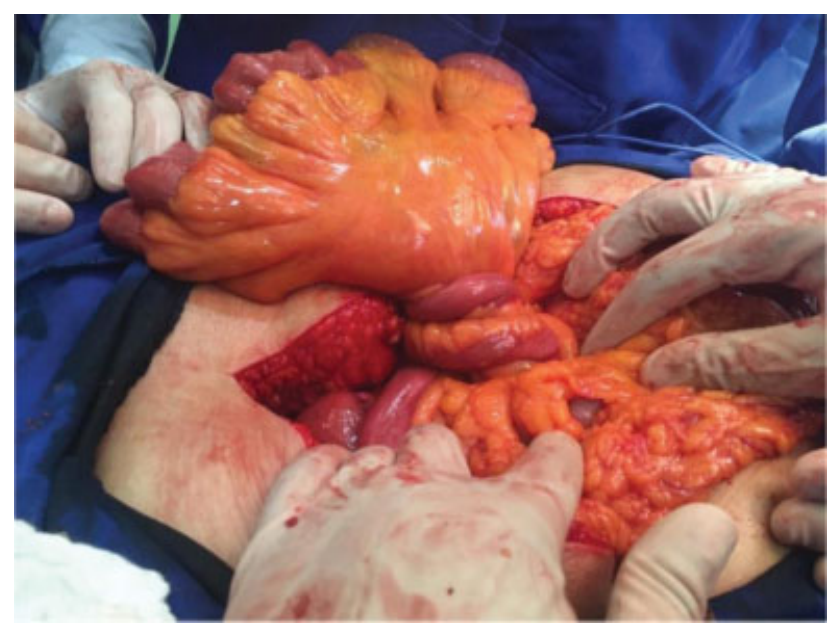

Fig. 3 Mesenteric torsion of $720^{\circ}$ around the superior mesenteric artery.

diverticulum ( - Figure 4) $40 \mathrm{~cm}$ from the angle of Treitz, and upper cecum with minimum epiploic adhesions. Additional diverticula were found in the large intestine without complications. The Ladd procedure was performed to untwist the mesentery, no evidence loops were affected, mesenteric defect sutured, diverticulectomy with linear stapler and TACTICAL appendectomy.

The patient discharged on the third postoperative day; she was assymptomatic six months following procedure, and remains in outpatient follow-up.

\section{Discussion}

Intestinal malrotation is a congenital anomaly caused by the non rotation and fixation of the mesentery or their incomplete rotation along the posterior abdominal wall during embryonic development. It is characterized by the duodenojejunal flexure positioned on the right side of the abdominal cavity, the cecum, and the ascending colon along the midline or left side of the cavity. There is also a narrowing and shortening of the mesentery, which may lead to volvulus 


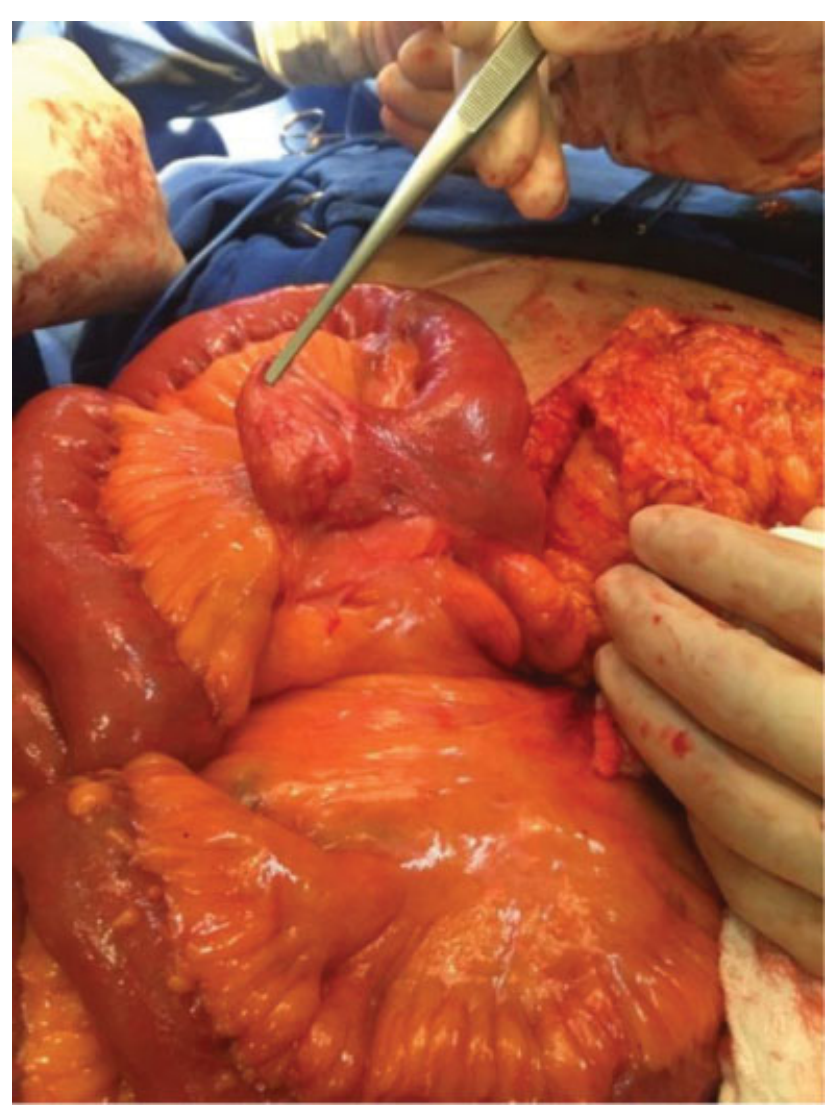

Fig. 4 Meckel diverticulum.

and peritoneal stalks (Ladd bands), which can compress the duodenum and cause chronic duodenal obstruction. ${ }^{7}$

This malformation comprises different subtypes: nonrotation, malrotation, reverse rotation, and mesocolic hernia. It is frequently associated with other congenital anomalies, most commonly intestinal atresia, Meckel diverticulum, intussusception, Hirschsprung disease, congenital heart disease, and anorectal malformations. In the case herein reported, the malformation was associated with Meckel diverticulum. ${ }^{8}$

It is estimated that 1 in 500 newborns present intestinal malrotation; ${ }^{8} 80 \%$ of the cases become symptomatic within the first month of life, and $90 \%$ are diagnosed within the first year. ${ }^{9}$

It is a rare disease in adults, reported in just $0.0001 \%$ to $0.19 \%, 8$ of the population; however, as most of the affected adult population is asymptomatic or presents non-specific symptoms, this number may be underestimated. The malformation is reported equally for men and women.

In newborns, symptoms like bowel obstruction with bilious vomiting are frequent; cases in adults are mostly asymptomatic. Some patients report chronic abdominal discomfort with no apparent cause, and the pain is commonly attributed to other pathologies prevalent in this age group. ${ }^{9,10}$

In symptomatic cases, symptoms may present acutely or chronically. Vomiting, as well as pain without abdominal distention that may progress to ischemia, with intestinal necrosis and peritonitis, are associated with acute symptoms. In general, a good review of the patient's medical history can help identify the presence of mild, intermittent symptoms prior to an acute episode.

Chronic cases are characterized by vague symptoms, such as cramping and recurrent vomiting, ${ }^{1,10}$ and, similar to the case herein reported, intermittent complaints with acute worsening, but otherwise without other complications.

A high degree of clinical suspicion is necessary to establish a diagnosis, since this is an extremely rare disease, with vague and non-specific symptoms. Therefore, complementary imaging is critical to make a diagnosis.

Contrast radiography of the upper gastrointestinal tract is the gold standard to diagnose intestinal malrotation, with an accuracy between $80 \%$ and $100 \%{ }^{1}$ These images enable the identification of the duodenojejunal flexure located to the right of the spinal column. Other tests include contrasted abdominal $\mathrm{CT}$, abdominal ultrasound (US) and angiography/CT angiogram.

The treatment of adult patients with intestinal malrotation depends on the form of the initial presentation. In cases of acute presentation, with signs of peritonitis or general involvement, surgical intervention is required once the patient has been stabilized.

In chronic cases, there is no standard approach; the treatment may be symptomatic or surgical. ${ }^{11,12}$ Patients with this condition are considered candidates for further progression to bowel obstruction, with ischemia or intestinal necrosis. Given the risks, some professionals recommend performing elective laparotomy and the Ladd procedure. $^{5,9}$

The Ladd procedure has been the most widely-recommended procedure by both general and pediatric surgeons since 1936. It has been proven to improve symptoms and to reduce the risk of volvulus and intestinal ischemia. ${ }^{13}$ The surgical procedures vary according to the intraoperative findings and the types of associated malformations, if any.

The Ladd surgery consists of releasing the existing adhesions, mobilizing the duodenum and right colon, releasing and enlarging the pedicle of the upper mesenteric vessels, and performing a prophylactic appendectomy. ${ }^{14}$ Other surgical procedures include duodenopexy, cecopexy, and lysis of the adhesions.

the treatment decisions in asymptomatic patients should be based on a case-by-case assessment of associated risks and benefits. In the case herein reported, the patient presented with a previous diagnosis of intestinal malrotation, and the decision was made to pursue watchful waiting. The patient subsequently underwent surgical treatment on account of worsening symptoms, notably pain that could only be controlled trough the administration of prescription opioids and consequent deterioration of the patient's quality of life. Bowel resection was deemed unnecessary, because there was no ischemia/necrosis.

Corrective surgery ensures partial to total relief of symptoms, especially abdominal pain. In the case herein reported, the patient was completely relieved of her symptoms; there was no report of postoperative complications, and the patient returned to her regular eating habits, consequently experiencing a healthy weight gain. 


\section{Conclusion}

Intestinal malrotation is a pathology often diagnosed in children, but rarely in the adult population. Nonetheless, it is extremely important due to its possible complications, and it should always be considered as a differential diagnosis among patients with chronic and nonspecific abdominal symptoms.

This present report aims to raise awareness of this pathology and the need of their clinical suspicion in cases of non-specific symptoms of abdominal pain in adults. It is also meant to add to the understanding of embryology and abdominal anatomy to contribute to to the rediagnosis of this condition and to treat it as early as possible. More largescale follow-up studies are needed to determine the best treatment strategy in asymptomatic adults to establish the best recommendations for the Ladd procedure.

\section{Conflict of Interests}

The authors have no conflict of interests to declare.

\section{References}

1 Araújo URMF, El Tawil II. Má rotação intestinal em adulto: relato de caso. Arq Bras Cir Dig 2011;24(01):86-88

2 Zissin R, Rathaus V, Oscadchy A, Kots E, Gayer G, Shapiro-Feinberg $\mathrm{M}$. Intestinal malrotation as an incidental finding on $\mathrm{CT}$ in adults. Abdom Imaging 1999;24(06):550-555

3 Bezerra AM, Yamaguchi OY, Gonçalves LA, Nascimento BAC, Sassatani AS, Assef JC. Má rotação intestinal em adultos: um relato de caso e revisão da literatura. Arq Med Hosp Fac Cienc Med Santa Casa São Paulo. São Paulo. V.64. n.1, p.61-64, jan/abr.2019
4 Ayane GN, Kadimo K. Diagnosis and surgical management of congenital intestinal malrotation presenting with midgut volvulus in an adult: high index of suspicion (case report). Pan Afr Med J 2018;29:154

5 Moldrem AW, Papaconstantinou H, Broker H, Megison S, Jeyarajah DR. Late presentation of intestinal malrotation: an argument for elective repair. World J Surg 2008;32(07):1426-1431

6 Gamblin TC, Stephens RE Jr, Johnson RK, Rothwell M. Adult malrotation: a case report and review of the literature. Curr Surg 2003;60(05):517-520

7 U. of M. C. Moore. Persaud, T.V.N. O Sistema Digestivo. In Embriologia Clínica, 8a edição Elsevier; 2008:226-235

8 David DA, Folgado A. Má rotação intestinal no adulto. Trabalho final mestrado integrado em medicina Julho/2017

9 Kafadar MT, Cengiz AY, Çaviş T, Bilgiç İ, Nadir I. Incidental intestinal malrotation in an adult: Midgut volvulus. Turk J Surg 2018;34(04):337-339

10 Husberg B, Salehi K, Peters T, et al. Congenital intestinal malrotation in adolescent and adult patients: a 12-year clinical and radiological survey. Springerplus 2016;5(01):245

11 Malek MM, Burd RS. The optimal management of malrotation diagnosed after infancy: a decision analysis. Am J Surg 2006;191 (01):45-51

12 Fu T, Tong WD, He YJ, Wen YY, Luo DL, Liu BH. Surgical management of intestinal malrotation in adults. World J Surg 2007;31 (09):1797-1803, discussion 1804-1805

13 Covey SE, Putnam LR, Anderson KT, Tsao K. Prophylactic versus symptomatic Ladd procedures for pediatric malrotation. J Surg Res 2016;205(02):327-330

14 Matzke GM, Dozois EJ, Larson DW, Moir CR. Surgical management of intestinal malrotation in adults: comparative results for open and laparoscopic Ladd procedures. Surg Endosc 2005;19(10): 1416-1419 